\title{
Structural changes in activated wood-based carbons: correlation between specific surface area and localization of molecular-sized pores
}

\author{
Andreas Herzog ${ }^{1, *}$, Boris Reznik ${ }^{2}$, Tengfei \\ Chen $^{2}$, Thomas Graule ${ }^{1}$ and Ulrich Vogt ${ }^{1}$ \\ ${ }^{1}$ Swiss Federal Laboratories for Materials Testing and \\ Research (EMPA), Department of High Performance \\ Ceramics, Duebendorf, Switzerland \\ 2 Laboratorium für Elektronenmikroskopie, Universität \\ Karlsruhe, Karlsruhe, Germany \\ ${ }^{*}$ Corresponding author. \\ Andreas Herzog, Swiss Federal Laboratories for Materials \\ Testing and Research (EMPA), Department of High \\ Performance Ceramics, Ueberlandstr. 129, CH-8600 \\ Duebendorf, Switzerland \\ E-mail: ceramics@empa.ch
}

\begin{abstract}
Samples of maple were pyrolyzed and subsequently activated by carbon dioxide at different temperatures for various dwell times. The changes in wood structure were characterized by nitrogen adsorption isotherms, transmission electron microscopy (TEM) with selectedarea electron diffraction (SAED), and scanning electron microscopy (SEM). Increasing pyrolysis temperatures promoted increased crystallization of graphitic wood components and mineral-like phases. The average pore diameter derived from nitrogen adsorption isotherms approximately correlated with the results obtained by high-resolution SEM and TEM. The highest surface area was found for samples containing considerable amounts of nanoperforated pit membranes located in intervascular pitting. High-resolution TEM examinations of membrane regions showed foam-like clusters with an average size of $1.7 \mathrm{~nm}$, which are attributed to the selective influence of $\mathrm{CO}_{2}$ activation on pyrolyzed cellulose and lignin.
\end{abstract}

Keywords: activation; BET surface area; charcoal; electron microscopy (EM); graphite; pyrolysis; scanning electron microscopy (SEM); selected-area electron diffraction (SAED); transmission electron microscopy (TEM).

\section{Introduction}

Activated carbon sorbents obtained from pyrolysis of wood are versatile materials that contain interconnected pores of molecular dimensions (i.e., $<2 \mathrm{~nm}$ ). These materials possess large surface area, typically $300-1500 \mathrm{~m}^{2} \mathrm{~g}^{-1}$. This fact is of great technological importance, for example, for adsorption and heterogeneous catalysis (Bansal et al. 1988), water cleaning (Rodrigez-Reinoso 1997), production of double-layer capacitors (Endo et al. 2001; Lozano-Castelló et al.
2003), and for the adsorption and storage of gas molecules (Sadoway and Mayes 2002; Züttel and Orimo 2002).

The initial structure of hardwood is anisotropic and heterogeneous due to the complex variation of cellular morphology, as well as the spatial distribution of organic and inorganic components (Fengel and Wegener 1989; Byrne and Nagle 1997). The wood cell wall is described as an arrangement of layers of different thickness, such as the compound middle lamella $(\mathrm{CML})$ and three secondary wall layers (S1-S3). These regions clearly differ in terms of macromolecular composition: the cell wall with $\mathrm{S} 2$ and S3 layers has $75 \%$ cellulose and polyoses, $25 \%$ lignin; and the membrane has a similar composition to the CML (41\% cellulose and polyoses, 59\% lignin) (Fengel and Wegener 1989).

The inorganic or mineral content (e.g., Ca, K, Mg, Si, $\mathrm{P}, \mathrm{Cl}$ ) of wood is relatively low and rarely exceeds $1 \%$ for wood from temperate climates and $5 \%$ for tropical wood (Fengel and Wegener 1989). The mineral inclusions are found within axial and ray parenchyma cells and fibers (Wagenführ 1989).

The chemical properties and microstructure of woodbased activated carbon have been extensively studied (Blazewicz et al. 1999; Pulido-Novicio et al. 2001; Szczygielska et al. 2001; Pastor-Villegas and Duran-Valle 2002). However, there are no data demonstrating a correlation between the specific surface area and localization of molecular-sized pores in relation to hierarchical organization and chemical composition of pyrolyzed wood before and after activation steps.

The aim of the present study was to identify a correlation between the specific surface area, wood morphology and composition both after pyrolysis and after subsequent activation. To reveal the relative trends of structural changes in terms of compositional differences, the cell wall and the pit membrane of intervascular pitting in maple wood were chosen as model subjects. Special attention was paid to understanding the relationship between the perfection of graphitic piles (formation of stacks with turbostratic basic structural units) on one hand, and the shape and diameter of pores on the other.

\section{Experimental}

\section{Materials}

Samples of sycamore maple (Acer pseudoplantanus L.) were cut into squares with a cross-section of $50 \mathrm{~mm}^{2}$ and a thickness of $10 \mathrm{~mm}$. Pyrolysis was carried out under nitrogen (Carbagas, quality 99.995) in a high-temperature furnace (Carbolite CTF 16/75 SiC tube) according to the following program: 


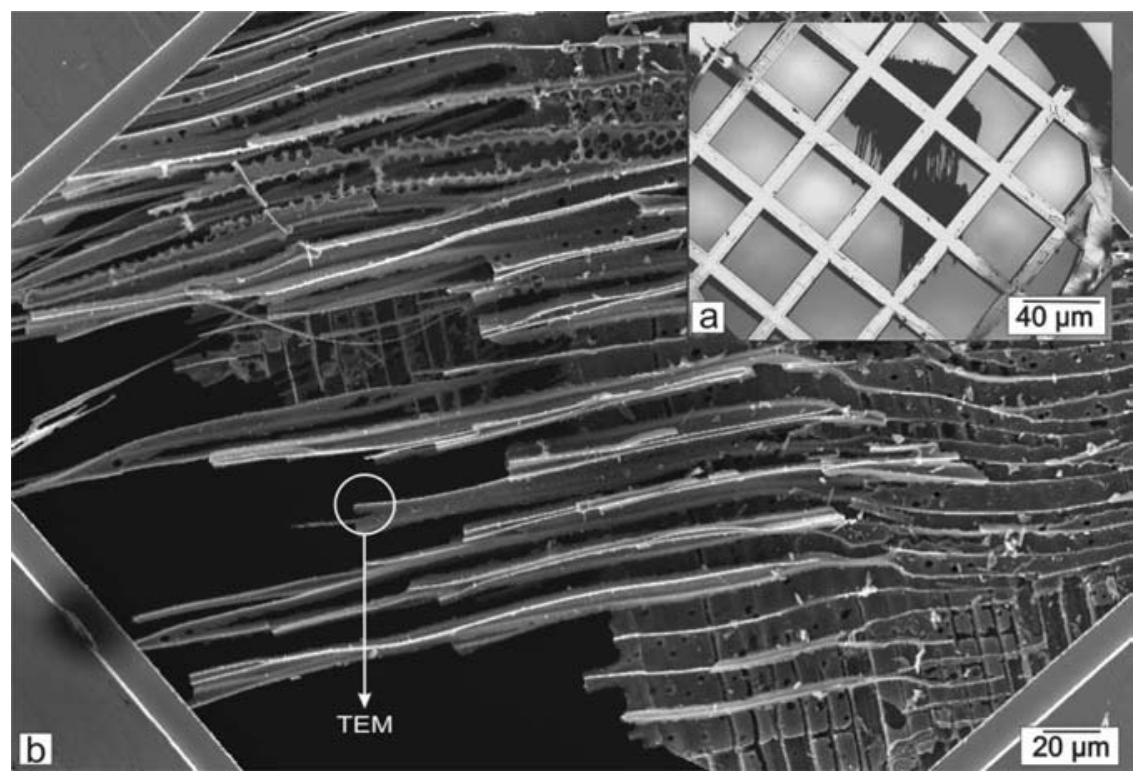

Figure 1 SEM micrographs of the folding TEM copper grid with (a) a piece of pyrolyzed maple wood and (b) an area (indicated by the white circle) containing electron-transparent fibres.

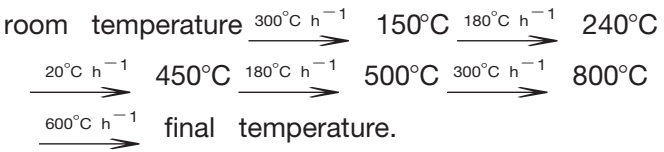

The final temperature was either 1100 or $1575^{\circ} \mathrm{C}$, and cooling was performed after reaching these temperatures. For the main pyrolysis region between 240 and $450^{\circ} \mathrm{C}$, the program used a slow heating ramp to avoid material cracking.

In the subsequent step, pyrolyzed samples were activated by $\mathrm{CO}_{2}$ with a heating ramp of $10^{\circ} \mathrm{C} \mathrm{min}{ }^{-1}$ to a final temperature $900^{\circ} \mathrm{C}$ for dwell times of 0 and $10 \mathrm{~min}$. Pyrolyzed samples were placed widely apart to allow free $\mathrm{CO}_{2}$ gas flow between them in a tube furnace (Carbolite CTF 16/75 $\mathrm{SiC}$ tube), while $\mathrm{CO}_{2}$ was passed at a constant flow rate $\left(50 \mid \mathrm{h}^{-1}\right)$ through the tube $(d=70 \mathrm{~mm})$. Activation results were quantified in terms of the mass loss of the samples by weighing them before and after the activation process. It should be noted that the dwell times quoted in the text for activation with $\mathrm{CO}_{2}$ are not identical to the true activation time actually experienced by the samples during heat treatment (see Figure 2). With the endothermic reaction of carbon and $\mathrm{CO}_{2}$ following the Boudouard equilibrium, the formation of $\mathrm{CO}$ and therefore activation starts at a temperature of approximately $700^{\circ} \mathrm{C}$. The exact point of the equilibrium is difficult to adjust and the driving force for the activation reaction increases gradually with increasing temperature between 700 and $900^{\circ} \mathrm{C}$. Therefore, the activation process begins before reaching the final activation temperature of $900^{\circ} \mathrm{C}$. Consequently, the true activation time is always greater than the dwell time; however, the latter is exactly definable and is consequently quoted in the text.

\section{Sample characterization}

Characterization of the bulk surface The specific surface area was determined using nitrogen adsorption isotherms at $77 \mathrm{~K}$ using a Coulter SA 3100 surface and pore size analyzer. The nitrogen surface area was calculated using the BET equation for a pressure range of $p / p_{0}=0.0033-0.1$ bar.

Microscopy Thin slivers of pyrolyzed (and activated) wood fibers were fractured from the bulk samples and placed onto folding TEM copper grids (Figure 1). This preparation allowed marking of thin transmittable wedge-shaped areas of the trans- versal cell wall or membranes from intervascular pittings. Therefore, the same regions of interest could be studied by SEM and TEM. Moreover, this preparation procedure avoids the formation of artefacts by ion thinning (Rodriguez-Reinoso et al. 1995; Hata et al. 2000).

TEM observations at low and medium magnifications and zero-loss filtered SAED were carried out in a 120-keV LEO EM 912 Omega TEM equipped with an electron energy-loss spectrometer with an entrance slit of approximately $5 \mathrm{eV}$. It allows selection of only the primary, zero-loss beam and therefore filters coherent from non-coherent (diffuse) electron scattering. This leads to an enhanced background/signal ratio (contrast) in SAED patterns.

HRTEM was carried out using a 200-keV Philips CM 200 FEG/ ST electron microscope. Scherzer resolution (point-to-point resolution) was $0.24 \mathrm{~nm}$. Approximately five samples were analyzed for each treatment procedure. A minimum of 50-100 images were acquired and sorted according to different morphological types of nanosized carbon structures.

The spatial morphology was analyzed using a LEO 1530 Gemini scanning electron microscope equipped with a Schottky fieldemission gun without conductive layers.

In all microscopy observations, the percentage hit rate was determined as the number of images of frequently observed

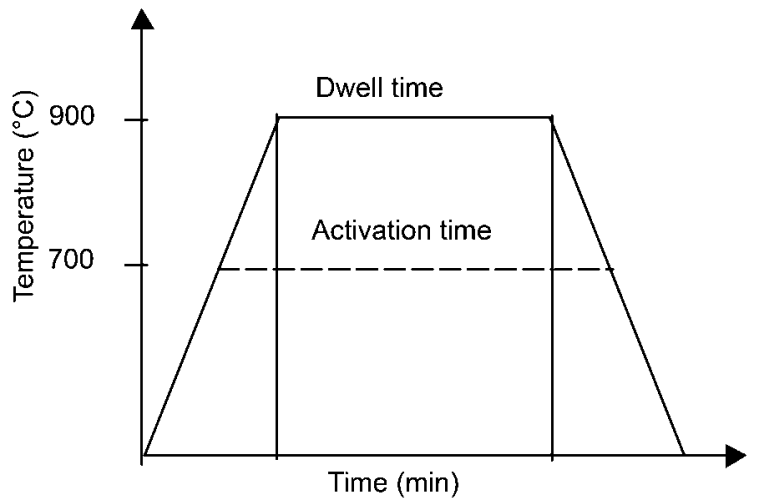

Figure 2 Time-temperature profile for activation with $\mathrm{CO}_{2}$. Note the difference in activation (starting at approx. $700^{\circ} \mathrm{C}$ ) and dwell time (starting at exactly $900^{\circ} \mathrm{C}$ ). 


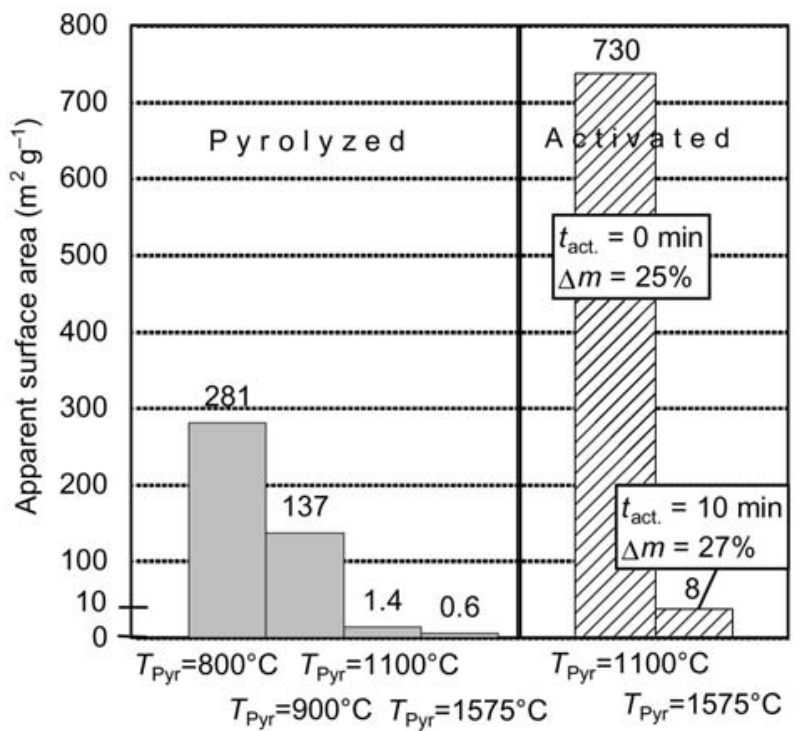

Figure 3 Apparent surface area as a function of pyrolysis temperature (filled columns) and subsequent activation in $\mathrm{CO}_{2}$ at $900^{\circ} \mathrm{C}$ (dashed columns). Note the different activation times to achieve similar burn-off $\Delta m$ for maple wood pyrolyzed at different temperatures.

structures (e.g., fracture elements of a given type in SEM images or carbon clusters of given size and morphology in HRTEM images) related to the total number of the micrographs acquired (approx. 30 images between $100 \times$ and $500000 \times$ ).

\section{Results}

\section{Determination of specific surface area}

The pyrolysis temperature has a distinct effect on the surface area of pyrolyzed wood, with higher pyrolysis temperatures generally leading to lower surface areas (Figure 3).

This parameter significantly influences the burn-off and the surface area achievable during activation. To reach the same burn-off during activation (pyrolysis temperature 1100 and $1575^{\circ} \mathrm{C}$ ), the dwell time has to be prolonged for samples obtained at higher temperatures. Although the final burn-off is similar after this procedure, the surface area achieved differs by two orders of magnitude. Very clear differences are found between the sample pyrolyzed at $1100^{\circ} \mathrm{C}$ and the sample subsequently activated by $\mathrm{CO}_{2}$ at $900^{\circ} \mathrm{C}$ for a dwell time of $0 \mathrm{~min}$, which exhibited the highest specific surface area (Figure 3). Therefore, the following SEM and TEM data mostly present representative results obtained for these samples.

\section{Fractography}

Figure 4 shows SEM images of maple pyrolyzed at $1100^{\circ} \mathrm{C}$. After heat treatment, fracture frequently takes place in the transverse direction (Figure 4a) and fibers, vessels, and rays can be observed at the surface. The cross-section of the cell walls of fibers and rays displays uniformly distributed plate-like units (Figure 4b). Highresolution micrographs revealed the presence of characteristic globular particles with the size of approximately
$20 \mathrm{~nm}$ (Figure 4c). The hit rate of the observed features is $90 \%$.

After subsequent activation by $\mathrm{CO}_{2}$ at $900^{\circ} \mathrm{C}$ for a dwell time of $0 \mathrm{~min}$, the fissured fracture surface in the tangential direction contains new details (Figure 5a) which were previously not observed (Figure 4). At the macroscopic level, fractured vessels with typical spiral thickening (marked by an arrow) are observed (area a1). A perforated vessel wall is evident in the form of delaminated membranes in the intervascular pittings (area a2 in Figure 5a). Caverns and well-shaped particles are observed in regions of the fiber walls (Figure $5 b$ ). According to EDX analysis, the particles contain $\mathrm{S}, \mathrm{Ca}, \mathrm{K}, \mathrm{Cl}$, and $\mathrm{O}$.

Figure 6 shows the details of a fractured intervascular pitting region frequently observed at lower magnification (Figure 5a, area a2). Closer inspection indicates that most of the bordered pits still consist of the pit membrane and borders on each side (numbered 1, 2 and 3). The residual layers (Figure 6a) exhibit a different contrast and contain different types of pores. High-resolution imaging of intermediate layer 2, which functions as a membrane in the pit (Figure 6b), reveals an extensive network of pores with diameters ranging from 3 to $20 \mathrm{~nm}$. Crystallized mineral particles of $2-5 \mathrm{~nm}$ can be observed in the membrane region.

\section{Transmission electron microscopy}

Selected-area electron diffraction Figure 7 shows the structural changes observed by SAED analysis in

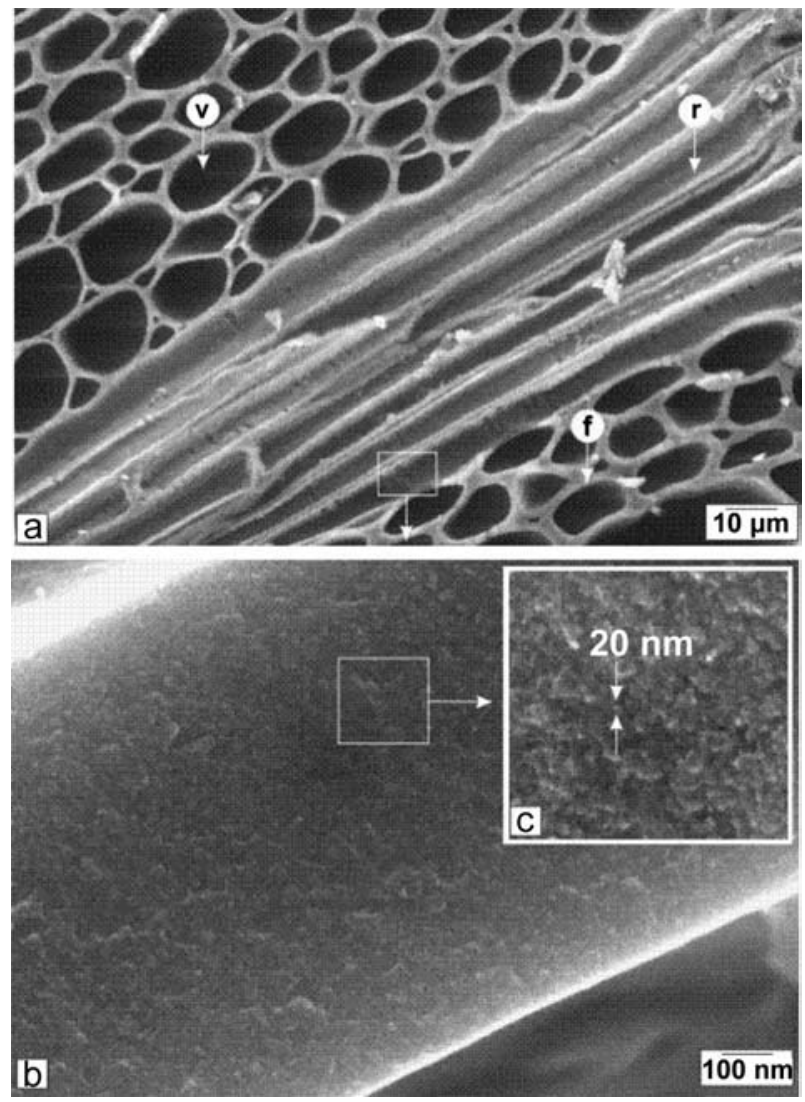

Figure 4 SEM micrographs of maple wood after pyrolysis at $1100^{\circ} \mathrm{C}$. (a) Transverse plane containing junction region between cross-cut fibers (f), vessels (v); and longitudinally cut ray cells (r); (b) cross-section of a cell wall; and (c) globular grains. 

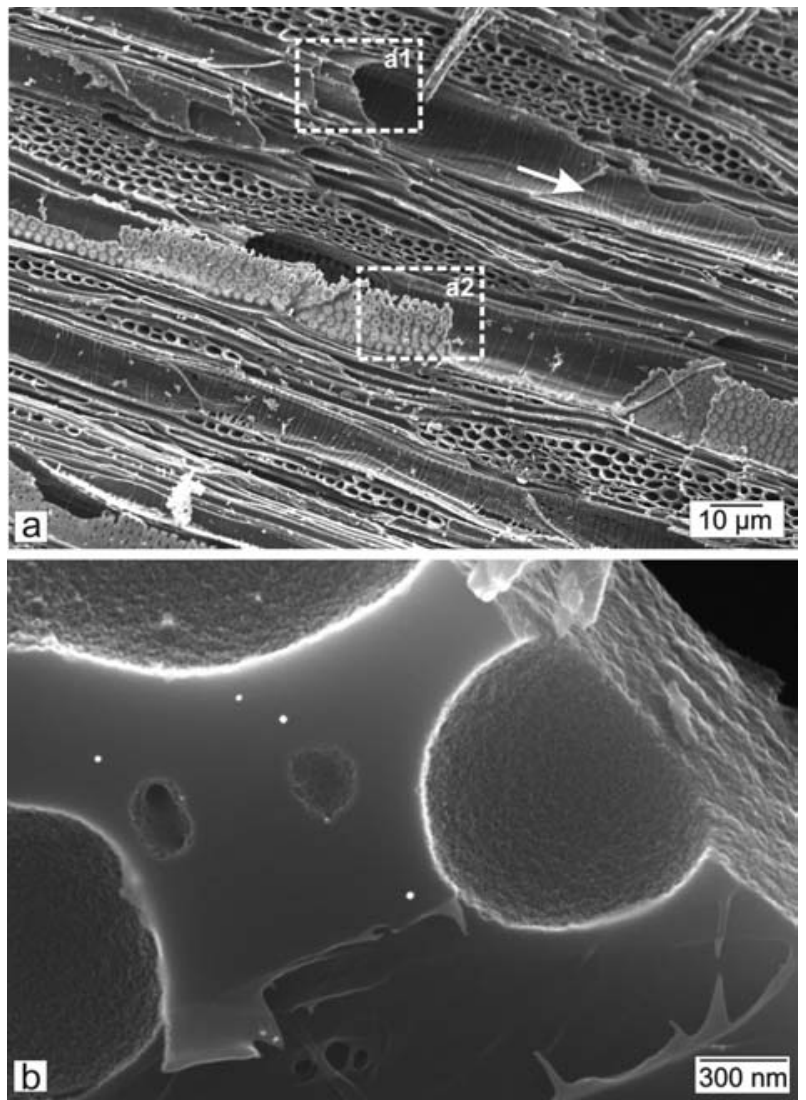

Figure 5 SEM micrographs of maple wood after pyrolysis at $1100^{\circ} \mathrm{C}$ and subsequent activation by $\mathrm{CO}_{2}$ at $900^{\circ} \mathrm{C}$ for a dwell time of 0 min. (a) Fractured vessels (area a1) with attached intervascular pittings (area a2) and spiral thickenings (arrow). (b) Magnification of area a1, with activation caverns and particles containing crystallized minerals. The hit rate is approximately $90 \%$.
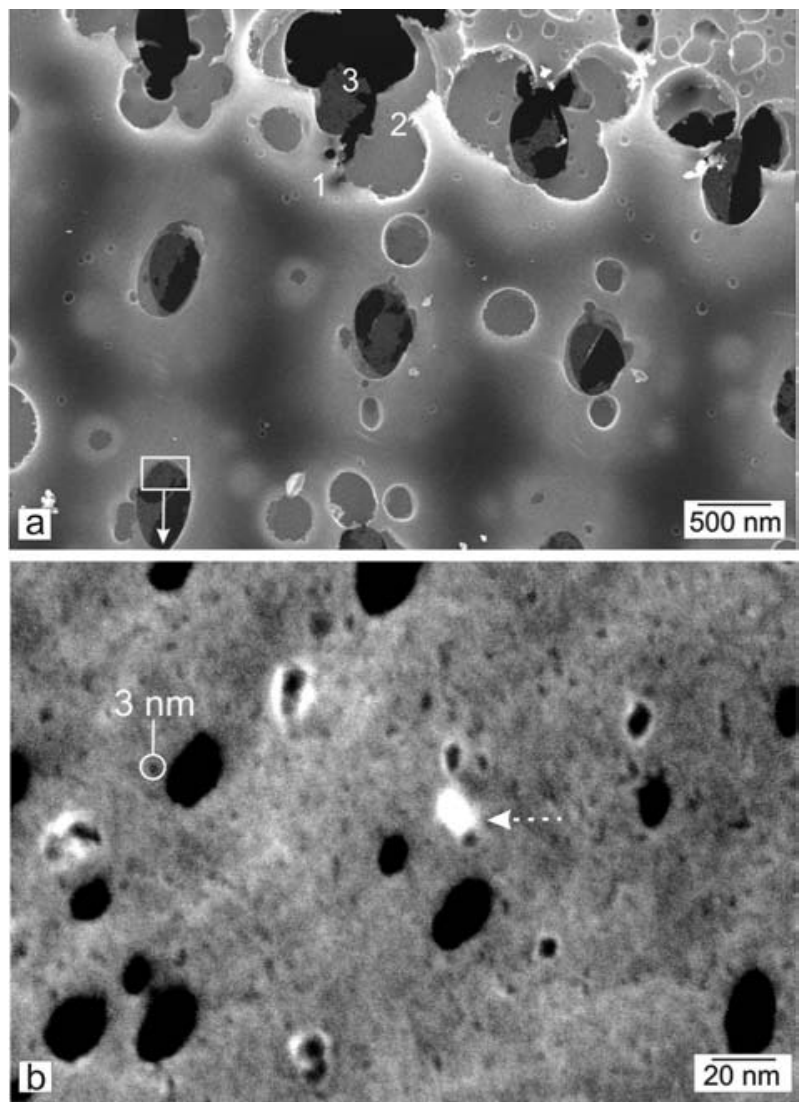

Figure 6 SEM micrographs of a delaminated membrane in the intervascular pittings (enlarged from region a2 shown in Figure 5a). (a) Three layers (numbered 1, 2 and 3) exhibit different contrasts; (b) magnified view of membrane layer 2 in (a) with molecular-sized pores (arrow) and particles (dashed arrow) containing crystallized minerals. The hit rate is approximately $90 \%$.
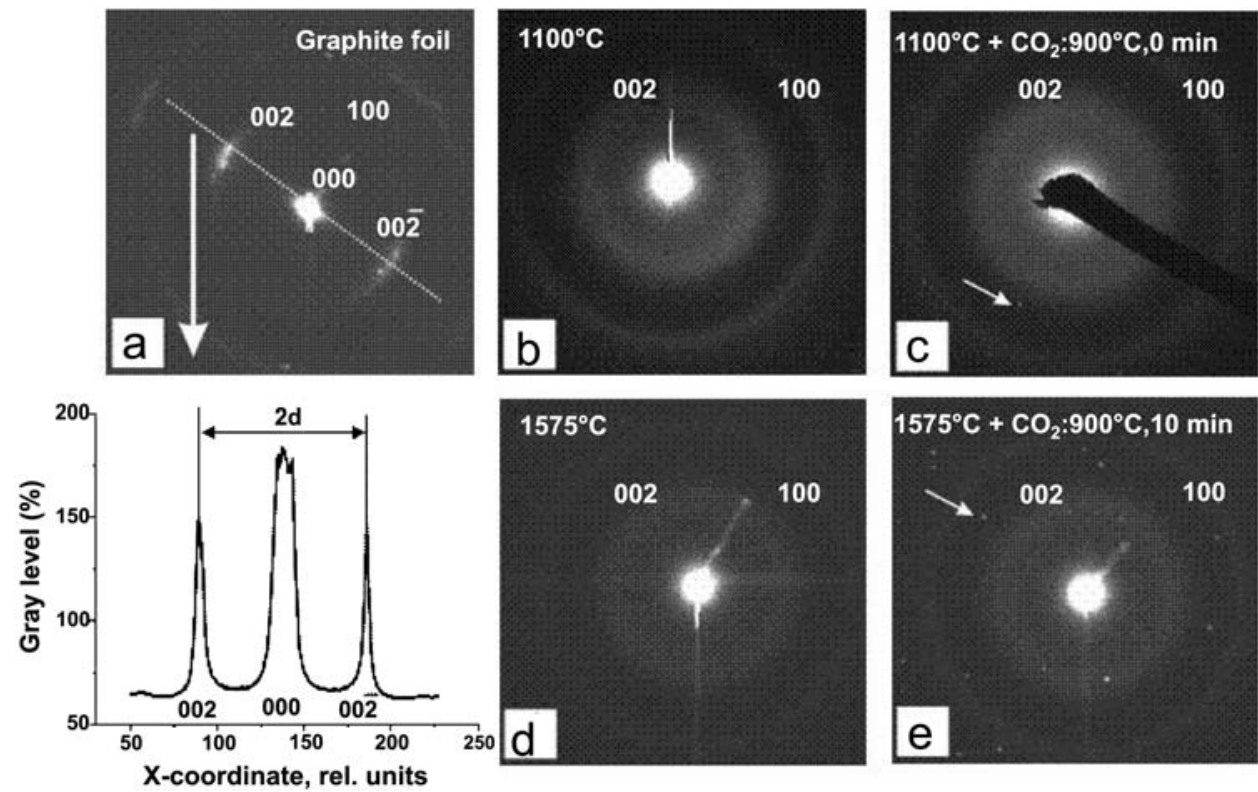

Figure 7 SAED patterns from (a) a reference graphite foil and $(b-e)$ treated wood samples. The dashed line in (a) indicates the [00/] direction of the intensity line scan used for evaluating the interplanar distance, as shown in the bottom of (a). The arrows in (c) and (e) indicate reflections from a mineral-like particle (details in the text). 


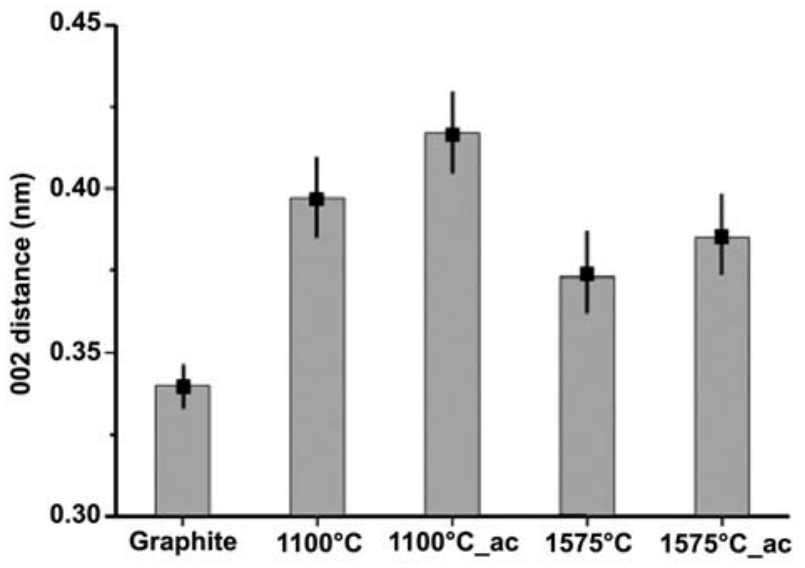

Figure 8 Variation of the average value of the (002) distance for maple samples treated under different conditions (pyrolysis temperature non-activated; ac, activated).

wood samples as a function of pyrolysis temperature and activation. In contrast to the strong diffraction reflections of graphite (Figure 7a), the (002) and (100) rings of SAED patterns are observed (Figure $7 b-e)$. No evidence of graphite crystals maintaining the previous cellulose microfibril orientation was found. This, however, may simply be a consequence of the fact that the relatively large aperture used for SAED analysis (1890 nm) only permits the observation of changes occurring at the submicrometer level. The appearance of very sharp reflections (arrows in Figure 7c,e) in the activated samples is remarkable. As in the case of the SEM observations (Figures 5 and 6), based on EDX analysis, it can be suggested that the origin of these reflections is associated with the presence of mineral-like inclusions containing $\mathrm{S}, \mathrm{Ca}, \mathrm{K}, \mathrm{Cl}$ and $\mathrm{O}$. It was found that these impurities increase in size as a function of temperature in the preliminary pyrolysis step.

The $d_{002}$ distance derived from the radial scans (refer to the diffraction pattern in Figure 7a) are plotted in Figure 8. Although there is $\pm 10 \%$ error in the estimation of the 002 spacing, a difference in the average value can be found. With increasing pyrolysis temperature, the 002 spacing moves towards that of the reference graphite foil $(0.34 \mathrm{~nm})$ and confirms a bulk increase in the degree of crystallization. After subsequent $\mathrm{CO}_{2}$ activation, the 002 spacing increases relative to the pyrolyzed state, i.e., activation creates some additional disorder. This may be caused either by the creation of additional nanopores during activation, or by parallel crystallization of minerallike inclusions. The latter option seems more likely, since activation of templates pyrolyzed at $1575^{\circ} \mathrm{C}$ caused an increase in 002 spacing similar to that observed for samples pyrolyzed at $1100^{\circ} \mathrm{C}$ and activated (Figure 8). However, for the templates pyrolyzed at $1575^{\circ} \mathrm{C}$, a comparatively minimal parallel increase in surface area was found (Figure 3 ), indicating the formation of negligible amounts of nanoporosity. Vice versa, it can be concluded that a higher pyrolysis temperature promotes agglomeration of alkali and alkaline earth metals within the organic template.

High-resolution transmission electron microscopy Figure 9 shows HRTEM micrographs taken from transverse sections of fiber cells (Figure 1) of samples pyrolyzed at $1100^{\circ} \mathrm{C}$. Interwoven stacks (Figure 9a), parallel ordered stacks (Figure 9b) and isotropic distributed stacks (Figure 9c) are observed. The interplanar distance between stacks is $\sim 0.4 \mathrm{~nm}$ and approximately correlates with the SAED data (Figure 8). No high-developed porosity was observed.

Figure 10 presents HRTEM results obtained for samples pyrolyzed at $1100^{\circ} \mathrm{C}$ and subsequently activated. After activation, relatively well-aligned stacks are present in the cell wall of fibers. The interplanar distance in the stacks smoothly varies between 0.27 and $0.47 \mathrm{~nm}$, indicating different degrees of crystallization (Figure 10a). Another typical nanostructure of this area can be represented by overlapped onion-shaped multiwalled clusters (Figure 10b). Figure 10c,d shows HRTEM images of membranes found in intervascular pittings. Features such as $3-10-n m$ pores, onion-shaped multiwalled clusters and particles containing $\mathrm{S}, \mathrm{Ca}, \mathrm{Cl}$, and $\mathrm{O}$ (black arrows in Figure 10c) are frequently observed. A remarkable structural feature in the form of foam-shaped clusters of $1.7 \mathrm{~nm}$ (Figure 10d) is frequently observed in the membranes of the intervascular pitting region.

\section{Discussion}

\section{Changes in specific surface area after pyrolysis and activation}

The largest value for the specific surface area $\left(730 \mathrm{~m}^{2} \mathrm{~g}^{-1}\right)$ was found for samples pyrolyzed at $1100^{\circ} \mathrm{C}$ and subse-
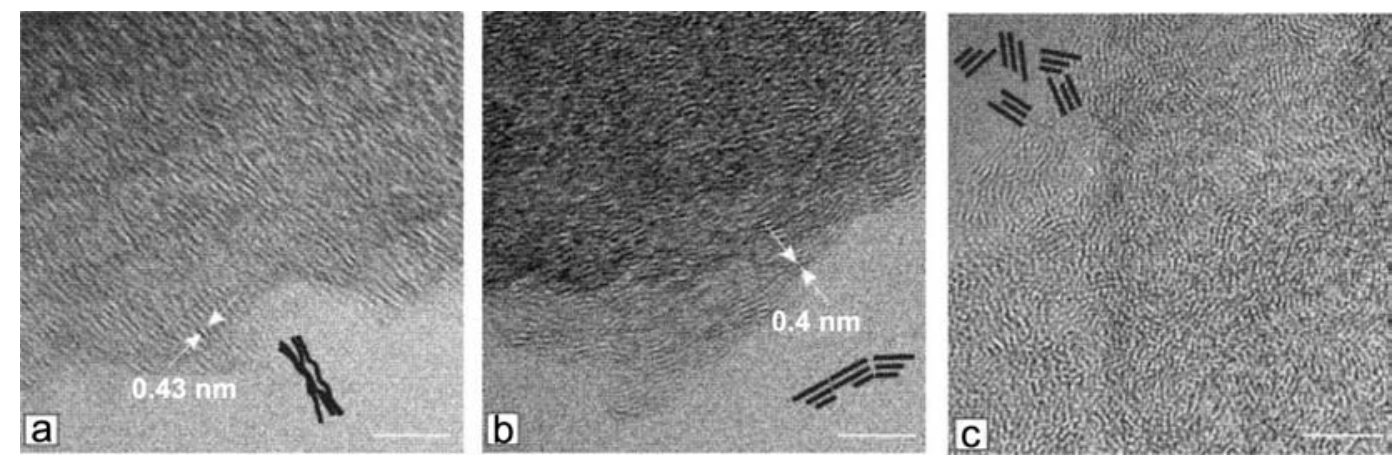

Figure 9 Typical nanoforms as observed by HRTEM in fibers regions after pyrolysis at $1100^{\circ} \mathrm{C}$ : (a) interwoven stacks, (b) parallel ordered stacks and (c) isotropic distributed stacks. Schematic representations of the nanoforms are shown in black in each image. The hit rates are approximately $50 \%$ for (a) and (b), and 30\% for (c) The scale bar represents $5 \mathrm{~nm}$. 

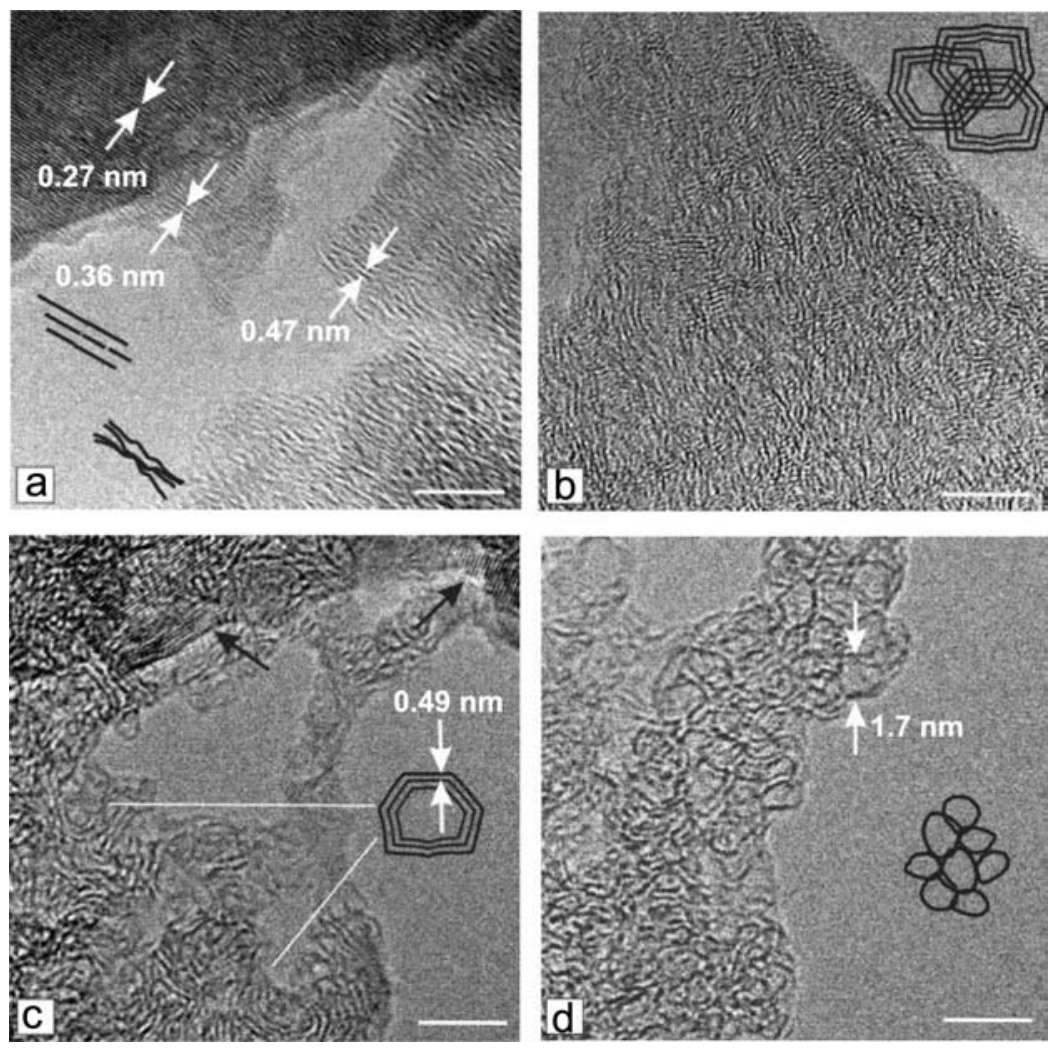

Figure 10 Typical nanoforms observed by HRTEM in fiber cell walls pyrolyzed at $1100^{\circ} \mathrm{C}$ and subsequently activated by $\mathrm{CO}_{2}$ at $900^{\circ} \mathrm{C}$ for a dwell time of 0 min: (a,b) stacks and onion-shaped multiwall clusters are taken from wall sections of fibers, while (c) onion-shaped multiwall clusters and (d) nanofoams are taken from membranes. Black arrows in (c) indicate mineral-like inclusions. Schematic representations of the nanoforms are shown in black in each image. The hit rates of the observed nanoforms are approximately $50 \%$. The scale bar represents $5 \mathrm{~nm}$.

quently activated by $\mathrm{CO}_{2}$ at $900^{\circ} \mathrm{C}$ for a dwell time of 0 min, with a weight loss of up to 25 wt. \%. For extended activation with weight losses up to 50 and 65 wt. \%, only a minor additional increase in surface area was obtained (100 and $320 \mathrm{~m}^{2} \mathrm{~g}^{-1}$, respectively). In contrast, very low weight changes of $15 \mathrm{wt} . \%$ are achievable at an activation temperature of $875^{\circ} \mathrm{C}\left(610 \mathrm{~m}^{2} \mathrm{~g}^{-1}\right)$. This disproportionate development of weight loss and surface area is more obvious by expressing the surface after certain burn-off in correlation to starting char [ $\mathrm{m}^{2} /(1-$ burn off) $\times g_{\text {char }}$, Figure 11]. According to the findings of Roudriguez-Reinoso et al. (1995) for olive stones, the parabolic curve represents first the opening and then maximum widening of pores. Changes in porosity are very likely and justified by the remarkable increase in surface area from 1.4 to $730 \mathrm{~m}^{2} \mathrm{~g}^{-1}$ in the charcoal. The activation is accompanied by a minor weight loss of 25 wt.\%. Later, the pore widening creates negligible amounts of new pores and surfaces, while over-proportional amounts of bulk materials are consumed by the activation process.

\section{Morphological, structural and chemical changes after pyrolysis and activation}

The perforated membranes of intervascular pittings (Figures 5 and 6 ) and molecular-sized pores with diameters ranging from 3 to $20 \mathrm{~nm}$ were observed in the membranes (Figure 6b). These values correlate well with those of the medium pore size estimated from the surface area measured by BET (Figure 3). By assuming ideal spherical pores, which are supposed to have vanishing small openings to the carbon surface, the following equation can be used:

Specific surface $=\frac{\text { surface }}{\text { weight }}=\frac{\pi d^{2}}{\rho V}=\frac{\pi d^{2}}{\rho \pi d^{3} \frac{1}{6}}=\frac{6}{\rho d}$

Assuming a carbon density of $1.5 \mathrm{~g} \mathrm{~cm}^{-3}$ after activation, a medium pore diameter of $5.5 \mathrm{~nm}$ can be calculated when a specific surface area of $730 \mathrm{~m}^{2} \mathrm{~g}^{-1}$ is used.

The structure of the pit membrane in the wooden state is known to be built up from non-oriented cellulose microfibrils (Robards 1970; Fengel and Wegener 1989). The cellulose content can be as low as $10 \%$ and gaps in between these microfibrils are filled with lignin and pectin (Wagenführ 1989). Since cellulose tends to form graphitic carbon at temperatures above $900^{\circ} \mathrm{C}$ and lignin yields amorphous carbon, structures developed during pyrolysis should be distinguishable after pyrolysis (Tang and Bacon 1964). However, differentiation of different types of carbon and their respective molecular sources in the wooden state is impossible by HRTEM, as shown in Figure 9. Nevertheless, because of the different sensitivities of various carbon structures to $\mathrm{CO}_{2}$ activation (Breval et al. 2002), selectivity of $\mathrm{CO}_{2}$ activation of cellulose- or lignin-rich materials can be expected. Preferred $\mathrm{CO}_{2}$ attack of lignin might explain the even distribution 


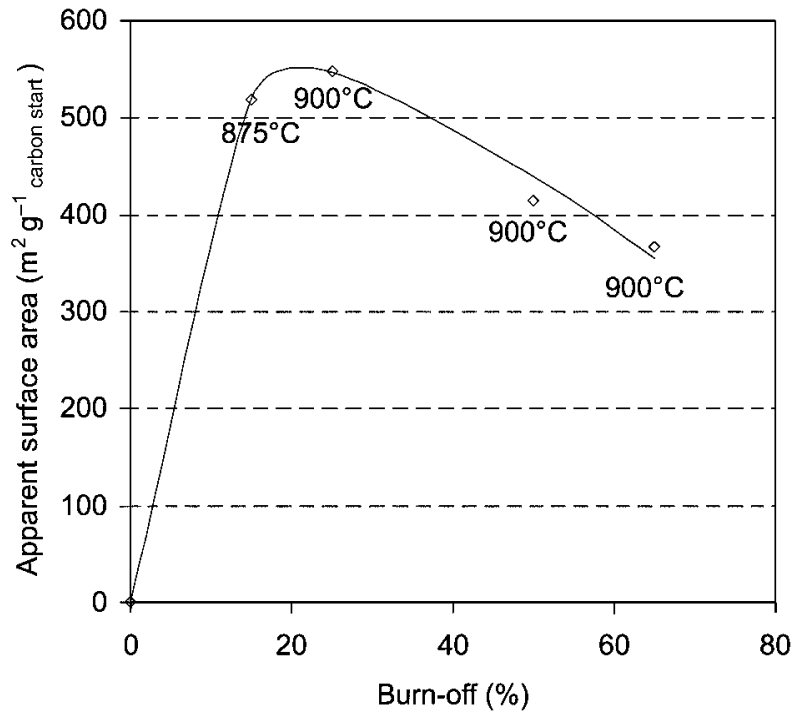

Figure 11 Development of apparent surface area related to the starting weight of carbon before activation as a function of burnoff during activation. Note the different activation temperatures of $875^{\circ} \mathrm{C}$ and $900^{\circ} \mathrm{C}$.

of pores in the membrane that arise from the lignin matrix, while a pattern of non-oriented carbonized cellulose remains in the membrane region (Figure 6b). Because of the high lignin content of the pit membranes, a highly porous area is created by the selective activation of this region. In contrast, in vessels and fibers, which contain much less lignin, only coarser porosity is found (Figure 5b).

The HRTEM data illustrate a basic difference in the nanoforms observed in the cell wall sections before (Figure 9) and after activation (Figure 10a,b). Stacked carbon structures are found in cellulose-rich regions; however, it is difficult to say whether they originate from lignin or cellulose precursors. After activation, additional onionlike multi-walled clusters are observed (Figure 10b). Similar clusters were found by Kurosaki et al. (2003) and Hata et al. (2000) in activated carbons. Further nanofoam clusters (Figure 10d) appeared in the pit membrane after activation. Obviously, these nanoforms are attributable to the selective influence of $\mathrm{CO}_{2}$ activation on pyrolyzed cellulose and lignin. The detailed mechanism of such morphological transformations is not known. Similar nano foams (isometrical cages) were observed by Huttepain and Oberlin (1990) in activated carbons and by Bourgeois and Bursill (1997) in carbonaceous materials found during the production of nanotubes.

\section{Conclusion}

The combination of gas adsorption analysis, SEM and TEM is a powerful analytical tool. Using these techniques, we demonstrated for the first time that fibers or ray cells and pit membranes in intervascular pitting show different pyrolysis and activation behavior. A relationship between the changes in specific surface area and morphological and structural transformations was found.

1. The highest surface area $\left(730 \mathrm{~m}^{2} \mathrm{~g}^{-1}\right)$ correlates with the formation of nanoperforated porous membranes (diameter of 3-20 nm) located in intervascular pittings when samples are pyrolyzed at $1100^{\circ} \mathrm{C}$ and then activated by $\mathrm{CO}_{2}$ at $900^{\circ} \mathrm{C}$ for a dwell time of $0 \mathrm{~min}$.

2. The presence of scrolled onion-like or foam-shaped carbon structures is associated with the selective influence of $\mathrm{CO}_{2}$ activation of cellulose- and ligninderived carbons. Evidence is provided here that pyrolyzed lignin exhibits higher $\mathrm{CO}_{2}$ reactivity compared with cellulose. As a consequence, different features can be observed after activation according to lignin and cellulose content.

3. Increased pyrolysis temperatures promote increased crystallization of graphitic wood components.

4. The activation process is accompanied by the crystallization of mineral-like phases, which causes structural disorder.

The changes observed in the morphological, structural and chemical features appear to be important indicators correlated to the enhanced adsorption capacity and therefore surface area of activated carbonized wood structures. With this knowledge, tailoring of pore sizes by controlled widening seems to be possible in a certain range. If this approach succeeds, the adsorptive properties of charcoal could be adjusted.

\section{References}

Bansal, R.C., Donnet, J.-B., Stoeckli, F. Active Carbon. Dekker, New York, 1988.

Blazewicz, S., Swiatkowski, A., Trznadel, B.J. (1999) The influence of heat treatment on activated carbon structure and porosity. Carbon 37:693-700.

Bourgeois, L.N., Bursill, L.A. (1997) High-resolution transmission electron microscopic study of nanoporous carbon consisting of curved single graphitic sheets. Philos. Mag. A 76:753-768.

Breval, E., Klimkiewicz, M., Agrawal, D.K., Ruskino, F. (2002) Pinhole formation and weight loss during oxidation of industrial graphite and carbon. Carbon 40:1017-1027.

Byrne, C.E., Nagle, D.C. (1997) Carbonization of wood for advanced materials applications. Carbon 32:259-266.

Endo, M., Maeda, T., Takeda, T., Kim, Y.J., Koshiba, K., Hara, H., Dresselhaus, M.S. (2001) Capacitance and pore-size distribution in aqueous and nonaqueous electrolytes using various activated carbon electrodes. J. Electrochem. Soc. 148:910-914.

Fengel, D., Wegener, G. Wood - Chemistry, Ultrastructure, Reactions. Walter de Gruyter, Berlin/New York, 1989, pp. 19-25.

Hata, T., Imamura, Y., Kobayashi, E., Yamane, K., Kikuchi, K. (2000) Onion like graphitic particles observed in charcoal. J. Wood. Sci. 46:89-92.

Huttepain, M., Oberlin, A. (1990) Microtexture of nongraphitizing carbons and TEM studies of some activated samples. Carbon 28:103-111.

Kuroskaki, F., Ishimaru, K., Toshimitsu, H., Bronsveld, P., Kobayashi, E., Imamura, Y. (2003) Microstructure of wood charcoal prepared by flash heating. Carbon 41:3057-3062.

Lozano-Castelló, D., Cazorla-Amorós, D., Linares-Solano, A., Shiraishi, S., Kurihara, H., Oyaet, A. (2003) Influence of pore structure and surface chemistry on electric double layer capacitance in non-aqueous electrolyte. Carbon 41: 1765-1775. 
Pastor-Villegas, J., Duran-Valle, C.J. (2002) Pore structure of activated carbons prepared by carbon dioxide and steam activation at different temperatures from extracted rockrose. Carbon 40:397-402.

Pulido-Novicio, L., Toshimitsu, H., Yasuji, K., Shuichi, D., Shigehisa, I., Imamura, Y. (2001) Adsorption capacities and related characteristics of wood charcoals carbonized using a one-step or two-step process. J. Wood Sci. 47:48-57.

Robards, A.W. Electron Microscopy and Plant Ultrastructure. McGraw-Hill, 1970.

Rodriguez-Reinoso, F., Molina-Sabio, M., Gonzalez, M. (1995) The use of steam and $\mathrm{CO}_{2}$ as activating agents in the preparation of activated carbons. Carbon 33:15-23.

Rodriguez-Reinoso, F. (1997) Activated carbon: structure, characterization, preparation and applications. In: Introduction to Carbon Technologies. Eds. Marsh, H., Heinz, E.A., Rodriguez-Reinoso, F. Universidad de Alicante, pp. 35-101.
Sadoway, D., Mayes, A. (2002) Portable power: advanced rechargeable lithium batteries. MRS Bull. 27:590-596.

Szczygielska, A., Burian, A., Dore, J.C. (2001) Paracrystalline structure of activated carbons. J. Phys. Condens. Matter 13:5545-5561.

Tang, M.M., Bacon, R. (1964) Carbonization of cellulose fibres 2: Physical property study. Carbon 2:221-225.

Wagenführ, W. Anatomie des Holzes. VEB Fachbuchverlag, Leipzig, 1989, pp. 154-163.

Züttel, A., Orimo, Z. (2002) Hydrogen in nanostructured, carbon related and metallic materials. MRS Bulletin 27:705-711.

Received May 12, 2005. Accepted October 4, 2005. 